\section{OPEN ACCESS}

\title{
Motives of labour migrations of foreign elite athletes to Polish table tennis clubs to Polish table temis clubs
}

\author{
Authors' contribution: \\ A) conception and design \\ of the study \\ B) acquisition of data \\ C) analysis and interpretation \\ of data \\ D) manuscript preparation \\ E) obtaining funding
}

Received: 24.04 .2021

Accepted: 01.06 .2021

\author{
Michał Lenartowicz*1ACDE $\mathbb{0}$, Anna Ciok ${ }^{2 B C D} @$ \\ ${ }^{1}$ Józef Pitsudski University of Physical Education in Warsaw, Poland \\ ${ }^{2}$ Physical Education and Sport Centre of University of Warsaw, Poland
}

*Correspondence: Michał Lenartowicz, ul. Marymoncka 34, 01-813 Warszawa; e-mail: michal.lenartowicz@awf.edu.pl

\begin{abstract}
The paper presents results of empirical study on elite foreign athletes working in Polish top table tennis clubs. It focuses on professional migration motives of elite table tennis players. In-depth interviews were carried out with 27 foreign table tennis players from 10 countries, who were playing for two top league clubs in Poland, and with 8 club coaches who were working with foreign players. Research was conducted during the 2014/2015 league season. The surveyed athletes came both from European countries of higher economic status than Poland and from outside Europe, from countries of lower economic status. A significant number of the surveyed players (11) arrived at Poland from China. The reasons why the surveyed players decided to come to Poland were varied and included both pull factors resulting from attractiveness of work abroad and factors pushing the players away from their home country sport system. Among the motives mentioned by the respondents, the major ones seem to be the desire to continue their professional career and to develop as players. Most of the respondents reported a few factors motivating them to come to Poland and play in the Polish table tennis league. Most often they gave several reasons altogether and it is not easy to classify them as exclusively one of the typologies of sport migrants presented in the literature. For some of the respondents, the decisive criterion was the high level of the Polish table tennis league, staying only slightly behind the French and German leagues. For others, good financial conditions offered by the Polish clubs and the possibility of improving living conditions were of key importance. Push factors were particularly important in the case of Asian players representing a very high level of sport skills, however slightly lower than the level of the Chinese national team.
\end{abstract}

Keywords: Sport migration, elite sport, athletes, migration motives, Poland

\section{Introduction}

Sport migrations concern the regional or global movement of players and coaches, for whom changes of place of work and residence have now become, especially at a higher level of sport and in the most globalised disciplines, a permanent element of their professional careers. In numerous sport disciplines, it is already teenagers who leave their homes in order to start work and improve their sporting skills. In many disciplines, players change sports clubs and places of residence moving within their country, between countries on the same continent, and between countries on different continents (Maguire and Bale 1994). According to Botelho and Agergaard (2011), sports migrants 
are not people controlled only by global and economic forces, but individuals who actively participate in developing the migration process and have specific motives to undertake migratory movements. The reasons for their migration are different. As is the case with many other workers, the most common type of migrant among sportspeople is the economic migrant. Motivated by the desire to earn better money, an athlete usually gets attached to the place of residence and treats his sports club as a place of work, which he will change when a better proposal appears. In addition to athletes - economic migrants, there are those who migrate with the intention of staying in the receiving country for many seasons, and sometimes even for good. Magee and Sugden (2002), whose typology of athletic migrants we are referring to, describes them as settlers. For some players, leaving their country of residence may be the only chance for achieving a sport career. They treat their departure and starting work in foreign clubs as a form of professional development, and not necessarily as a chance for higher earnings. This type of migrant is called an ambitionist. We may probably see some ambitionist sport migrants among new members of British national team prior to 2012 Olympic Games in London (citizenship changing athletes sometimes referred to in media as "plastic Brits"). It is also e.g. the case of elite mountaineer Denis Urubko, who left Russia to join one of the world-best teams in Poland to reach K2 summit in winter (Lenartowicz 2016). Some, described as nomadic cosmopolitans, try to become familiar with and experience many different cultures and nations. For some athletes, leaving their country of origin becomes necessary for personal or political reasons. In this case, a migrant athlete is referred to as an exile who voluntarily of being forced leaves his or her country of origin. Examples of such type of migrants could be found e.g. among many athletes who after the Second World War were mostly illegally permanently leaving communist regimes of Eastern Europe (Rider 2013, Pilarski 2014) who had complete state control also over amateur and semi-professional sport (Lenartowicz, Jankowski 2014). In addition to the above-mentioned types of migration, Magee and Sugden (2002) also present a celebrity superstar, i.e. a player who tries to gain the maximum media attention in the receiving country, looks for fame and glamour (modern-day example could be probably soccer player David Beckham).

Most international journal publications on the movement of athletes or other sports professionals, including migration motivations, focus on highly commercialised and globalised sports like e.g. football, basketball, rugby, ice hockey, cricket, handball, and track and field events (Rojo, Simiyu, \& Starepravo 2020, p. 550). In this paper we present a less commercialised and mediatized sports discipline in a sport semi-peripheral (in-between the sport core and peripheries using Wallerstein's world-system theory terminology) country like Poland. We have additionally focused on a sports discipline less popular in the media like table tennis and on foreign players working in Polish table tennis clubs. A specific feature of our research, due to domination of quantitative approach in sport migration research (Rojo, Njororai Simiyu \& Starepravo 2020, p. 551), is also its qualitative methodology. It allows for an in-depth analysis of the issue and understanding of the surveyed athletes' motives of professional migrations. Some other research findings from the complex research we refer to in this paper has been also presented also in other publications (e.g. Lenartowicz and Ciok 2020).

\section{Material and methods}

Study sample consisted of 27 foreign athletes (11 women and 16 man) from the highest Polish table tennis leagues, and their coaches. In the sport season 2014/2015 during which the research was conducted, the teams of both leagues included the total of 32 players without Polish citizenship. Out of the 11 surveyed female players, 6 were from China. Two Chinese-origin female athletes had Polish (interview 8 and 11) and 1 had German (interview 9) citizenship. The average age of the surveyed female players was 27 (the oldest one was 39 while the youngest 19). The majority of surveyed female players (73\%) lived permanently outside of Poland and travelled in for training sessions and matches. In the case of the surveyed male athletes, there were 5 Chinese players, including 1 Polish, 1 Japanese and 1 Slovak citizen. Interviews were also conducted with one Englishman, a South Korean, a Swede, a Belorussian, a Russian and an Indian, plus two Italians and two Czechs. The average age of male respondents was 29.6 (the youngest one was 18 and the oldest one 48). Five surveyed male athletes had children. 44\% of the surveyed male table tennis players stayed in Poland during the league season or lived permanently, and 56\% travelled in for matches. The respondents had very significant table tennis training experience. The average training period for women was 21 years, while for men it was 23 years.

Our study involved direct interviews with both the athletes and their coaches. In the case of the players, the interview was divided into two parts: qualitative (face-to-face, individual, in-depth interview based on interview dispositions) and quantitative (using a standardised questionnaire and focusing on respondents' social and sport 
Table 1. Interviewed table tennis female athletes with country of origin and nationality information (own research)

\begin{tabular}{lccc}
\hline No. & Interview no. & Country of origin & Nationality - country \\
\hline 1. & 1 & China & China \\
2. & 8 & China & Germany \\
3. & 9 & China & Czech Republic \\
4. & 10 & Czech Republic & Poland \\
5. & 11 & China & China \\
6. & 17 & China & China \\
7. & 18 & China & Slovakia \\
8. & 19 & Slovakia & Belarus \\
9. & 20 & Belarus & Ukraine \\
10. & 21 & Ukraine & Belarus \\
11. & 22 & Belarus & \\
\hline
\end{tabular}

Table 2. Interviewed table tennis male athletes with country of origin and nationality information (own research)

\begin{tabular}{lccc}
\hline No. & Interview no. & Country of origin & Nationality - country \\
\hline 1. & 2 & South Korea & South Korea \\
2. & 3 & Great Britain & Great Britain \\
3. & 4 & China & China \\
4. & 5 & China & Russia \\
5. & 6 & Russia & Belarus \\
6. & 7 & Belarus & Slovakia \\
7. & 12 & China & China \\
8. & 13 & China & China \\
9. & 14 & Japan & Czech Republic \\
10. & 15 & Czech Republic & Czech Republic \\
11. & 16 & Czech Republic & Italy \\
12. & 23 & Italy & Italy \\
13. & 24 & Italy & India \\
14. & 25 & India & Poland \\
15. & 26 & China & Sweden \\
16. & 27 & Sweden & \\
\hline
\end{tabular}

characteristics). We paid special attention to the interviewed Chinese or Chinese-origin table tennis athletes and analysed their motives or leaving China and seeking sport career development overseas. The questionnaire for the quantitative interview included 45 questions. Polish, English, and Russian versions of the questionnaire were used. These languages and the occasional support of Chinese translators were also used for the in-depth interviews with the athletes. All in-depth interviews with the coaches were carried out in Polish. Pilot study with two foreign table tennis players and a table tennis coach was carried out. Final field research was conducted during the league season 2014/2015, from September 2014 to May 2015, in 12 Polish cities that were hosting league matches. All research participants provided informed consent. In-depth interviews with the athletes and coaches were recorded and transcribed, and qualitative analysis was carried out with ATLAS.ti software. 


\section{Results}

Taking into account the diverse characteristics of the respondents' countries of origin (China, Korea, Russia, Sweden, India, Italy, Czech Republic, Ukraine, Belarus, Slovakia), we expected many different reasons for playing in the Polish league. Most of the respondents did not give one decisive factor motivating them to come to Poland and play in the Polish table tennis league. Most often they mentioned several reasons. Questions regarding this issue were divided into closed and open-ended, which gave the respondents greater freedom of expression and allowed to capture the potential differentiation of the motives of coming to Poland. In the case of closed-ended questions, the most frequently provided reasons for coming to Poland were the aspiration to continue a professional sports career (67\% of all answers), lack of opportunities for further development of sports skills in one's country (44\% of all answers) and the desire to obtain higher earnings (37\% of all answers) (Figure 1). Motives such as the desire to live in Poland ( $7 \%$ of all answers) or being persuaded by a coach or a fellow player ( $22 \%$ of all answers) were mentioned far less frequently.

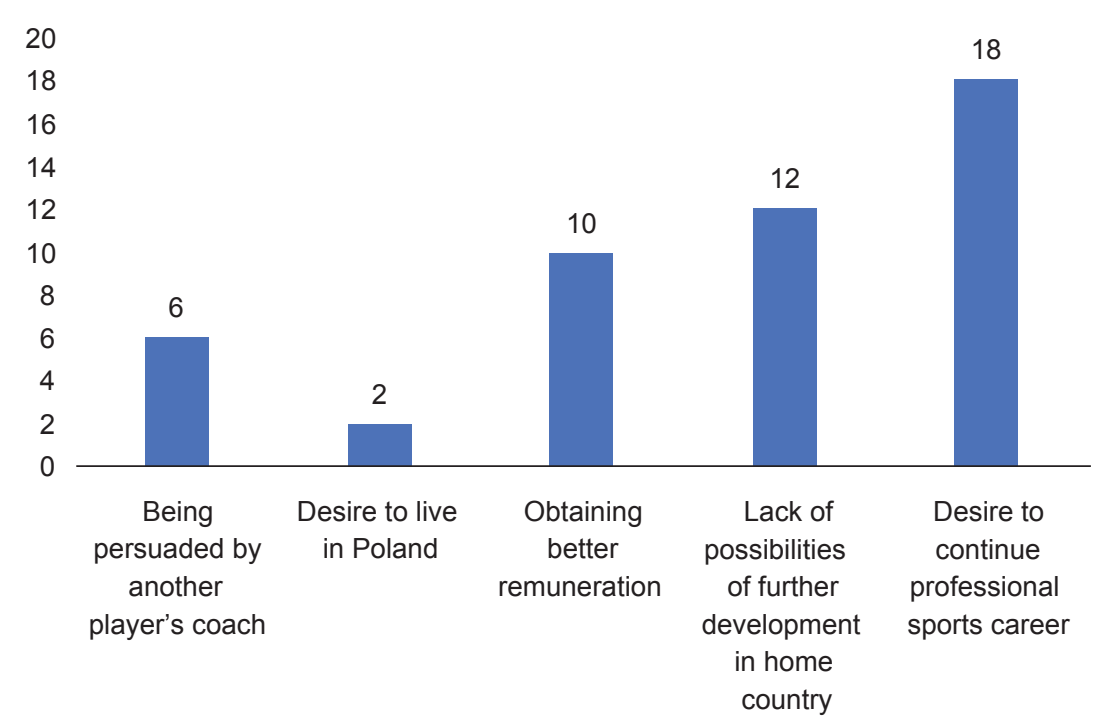

Figure 1. Reasons for playing in the Polish table tennis league indicated by the respondents (absolute values; multiple answers were possible)

In the case of indications regarding continuation of a professional sports career, the respondents' answers provide two main (sometimes co-occurring) types of motivation - positive and negative motivation. The aspiration to continue a career related to searching for opportunities to play with new, better players and opportunities to play in a different league than before, gaining new international experience, with a positive assessment of the sports environment, as well as a potential opportunity for development of sports skills in one's own country - we have defined all the above as positive motivation. Resorting to the statements from the open-ended questions, typical declarations in this respect are the answers of the respondents from interview 3 (England, male) and interview 24 (Italy, male): "There are a lot of strong players in Poland and a chance to play with new opponents"; "I want to play here in the Polish league because it is a good experience for me." Such motivation applied to only four of the surveyed players ${ }^{1}$.

However, for some respondents the desire to continue their careers was strongly linked with the lack of opportunities for further development in their country of origin. We considered it negative motivation arising from the dissatisfaction with the course of the career so far, and from the pessimistic assessment of the prospects for its further development. Twelve respondents $(n=27)$ admitted that they wanted to continue their sports career at home, but there were no more development prospects in their country of origin. An example could be the Chinese player from interview 5 . He wanted to continue playing in his own country, but it was not possible due to a large number of players representing a very high level: "It was difficult in China. They play hard there. I would have little chance". At the age of 17 this player had to make a decision about his further sports career. He wanted to continue playing

\footnotetext{
${ }^{1}$ Interview 3 (England, male), interview 10 (Czech Republic, female), interview 19 (Slovakia, female), interview 24 (Italy, male).
} 
table tennis, so after talking to his coach he decided to go to Poland to play in the Polish league. He justified his choice of the Polish league as follows:

"I wasn't admitted to the provincial team, I didn't really know where to train, but at that time players from one club from Poland came to China to train. I trained with them and felt good with them. Firstly, my coach asked me if I would like to play there, I agreed so he called and made an offer. And I agreed".

The pessimistic assessment of the possibility of continuing and developing a sports career also appeared in the statements of Chinese female players (interviews 8 and 9) and a player from Belarus (interview 7). The female player from interview 8 said: "I'd rather have little chance of continuing to play in China". It was similar in the case of player from interview 9: "So first of all, I wanted to continue my sports career. There were no prospects of further development for me in China". The player from Belarus (interview 7) gave a similar reason, saying that "the main reason was the desire to continue my sports career and the fact that we don 't have clubs in Belarus". An interesting case in this respect is the Chinese respondent from interview 4 who, disillusioned with his further career in China after not qualifying for the country's national team, started to look for a country where he could continue his career as a player. When looking for a club, he considered playing in Croatia or Poland, and eventually he was hired by a Polish club.

In the case of our research, negative motivation applied mainly to players from China (8 Chinese players with 12 motivations, which we classified as "negative motivations"). The remaining four players with negative motivations came from India and Belarus. The surveyed players from China represented a high level of skills in their country. When they were younger, they were in the so-called provincial representations, i.e. province teams - closed sports centres of all disciplines from a given province intended for outstanding players. The proof of intensity of work in these centres and their nature can be the statement of the player from interview 26: "During the year, there are 20 days of break for visiting, and on other days between 6 and 8 hours of training a day". These players occupied top positions in the provincial team competitions. For example, at the age of 7 the player from interview 1 ranked first in the Chinese championships, and then ranked fourth at the provincial level. The respondent said that if someone stands out in the club (primary school age) in China, they are offered training in the provincial team. Seven of the surveyed players from China ${ }^{2}$ represented a high level of sports skills. At the early school age they were selected for the provincial team, where they spent several years. This is how the respondent described the time spent as a member of the provincial team:

"Nobody watches you in the province, not like in the club, where the coach throws balls at you and watches how you train, if you yourself want to play there then play for yourself, and the coach is there just to observe in general. As a child, I wasn 't able to concentrate by myself, I was used to being forced to play by someone".

The trainer of the surveyed female player had a friend who was a table tennis coach in Poland and offered her to play in the Polish league. Already at the age of 14, the player was faced with the choice of continuing her career as a tennis player in another country or continuing her career in her own country with slim chances for top positions in Chinese sport. She finally decided to come to Poland and play in the league, but not for sport reasons mainly:

"At first, I wanted to get out of what was almost a prison as quickly as possible, I didn't want to play there, I just wanted to leave China when there was a chance".

From the analysis of interviews with the players of Chinese origin it can be concluded that the training system in China is based on very strong competition and a radical selection process. At some point, it includes only outstanding players. If, after several years of intensive training and sports competition, a player represents a very high level but still slightly lower than the level required by the Chinese national team, they have no prospects for further development of their sports skills. Possibly, they can be support in the specialised training of other promising players in the role of the so-called "silent hero". Such players have a very high sports potential, are aware of their high professional competences and are looking for opportunities to convert their sports capital into economic capital outside the Chinese sports market, which is closed to them and full of high-quality table tennis players. It is a sort of "overproduction" of high-quality professional athletes that finds an outlet outside China, where these athletes are hired and often stay for longer. Out of the 172 table tennis players who participated in the 2016 Olympics, 44 were

\footnotetext{
${ }^{2}$ Interview 1 (China, female), interview 4 (China, male), interview 5 (China, male), interview 7 (Belarus, male), interview 9 (China, female), interview 25 (India, male), interview 26 (China, male), interview 8 (China, female), interview 13 (China, male), interview 16 (Czech Republic, male), interview 22 (Belarus, female), interview 12 (Slovakia, born in China, male).
} 
from China and only 6 of them represented China. The remaining players represented twenty-one other countries out of the fifty-six countries participating in the Olympics in Rio de Janeiro ${ }^{3}$. During the 2012 London Olympics, only three countries in the women's category did not have a female athlete of Chinese origin in their team, i.e. Egypt, North Korea and Japan ${ }^{4}$. It is estimated that nearly 10 million Chinese play table tennis professionally, and about 300 million as a form of recreation. The Chinese national team is composed of 96 players -24 women and 24 men, and the same number of girls and boys. These players are sent to competitions in European countries or other countries outside China to find out how they cope on an international arena. On this basis, the team coaches assess whether a player has the potential to become a star ${ }^{5}$. If a team player does not do his best in training, does not perform well in international competitions or has some technical problems that inhibit his further development, the coach can always find another player with great sports potential outside the team who can quickly come into his place $^{6}$. A significant number of professional players in China creates great competition and contributes to a high level of skills of the national team players. Players who are considered too weak for the national team in China, when moving to a European country after some time they often represent other countries in European and world championships and during the Olympics. An example can be the players from our interviews 26, 9, 8 . The player who came to Poland in 2001, and in 2004 was granted Polish citizenship, in 2005 won the Polish championship in doubles and mixed doubles, in 2009 became the European vice-champion in doubles, the Polish champion in singles in 2012, the European champion in 2013, and also represented Poland at the London Olympics (interview 26). A female player of Chinese origin playing in the Polish league, with German citizenship, won the European championship and a gold medal at the Korea Open tournament (interview 9). The female player from interview 8 also represented a very high level of sports skills:

"I won the South China championship, and I ranked second for the whole China in the U14 category, then I won the annual Pro Tour, I was at the Olympics in Beijing, London and I also won Top 12 in Europe".

Among the players with negative motivation there was a tennis player from India (interview 25). His situation was different compared to the Chinese players. The Indian player was a member of the national team and previously played in the table tennis leagues in Slovakia and Germany. This is what he said about his coming to and living in Poland:

"I didn't have very good prospects for playing table tennis in my country, so I came here. Table tennis is not popular in India".

Two players from Belarus were in a similar situation. To give an example, let us refer to the statement of the player from interview 7, who wanted to continue his sports career abroad. He informed about the lack of clubs where he could play in Belarus and additional attractiveness of possible earnings in Poland as key reasons for his coming to Poland. As Maguire et al. (2002) write, Eastern European countries (not defined or specified in the text) have the reputation of being the main 'producers' of good players. This is where stronger European clubs are constantly looking for cheaper labour to import and make use of. In the East, the chances of development for a professional player are usually limited (Maguire et al. 2002, p. 35). The financial benefits of migrating to the West are a strong pull incentive and an important element in explaining migration patterns. The Polish table tennis league is one of the best in Europe ${ }^{7}$, so it may be very attractive, among others, to the surveyed players from Belarus, who do not have a professional table tennis league back at home.

It is worth adding that the interviews with the surveyed coaches reveal that the first foreign players who played in the Polish league came from the countries beyond the eastern border. The coach from interview 8 said: "The first foreigners were Russians and Ukrainians, it was in the early 1990s. There were also Belarusians". When recalling

\footnotetext{
${ }^{3}$ http://www.nytimes.com/2016/08/18/sports/olympics/ (retrieved: 12.12.2016).

${ }^{4} \mathrm{http}: / /$ www.nbcolympics.com (retrieved: 10.02.2018).

${ }^{5} \mathrm{http}: / /$ www.masatenisi.org/english/secrets.htm (retrieved: 20.11.2019).

${ }^{6} \mathrm{http}: / /$ www.masatenisi.org/english/secrets.htm (retrieved: 20.11.2019).

${ }^{7}$ European Champions League is dominated by German, Belgian, Austrian, Russian and French clubs, but in women table tennis, Polish clubs reached top positions. E.g. in the 2018/season club Enea Siarka Tarnobrzeg won Women's Champions League, while club SPAR Zamek Tarnobrzeg was second in 2015/2016 season and Siarka ZOT Tarnobrzeg in 2016/2017. In 2021 European table tennis clubs ranking, there were 13 Polish clubs noted, with Bogoria Grodzisk Mazowiecki club reported on 6th position (retrieved April 16, 2021, from http://www.eurotopteams.com/tt/EN/club.php). High quality of Polish table tennis league was also mentioned by our athlete and coach respondents.
} 
the beginnings of employing foreign players from Belarus and Ukraine, another coach said: "For sure, they were better and cheaper than Poles in the past" (interview 7).

When analysing the interviews with players who indicated the desire to continue their career as the reason for playing abroad, it is difficult to clearly define and classify the motivation of two of them, given that they themselves were not completely sure why they left their home countries. One is a Czech respondent (male, interview 15), who achieved everything in his home league, but was looking for opportunities to play against other, better opponents. He said during the interview:

"I played for the Czech Republic, won the league six times and decided that I had to change the league because this one was not strong enough. I was looking for another one, and the Polish league is strong, offers good money, good proportions, so I tried here and I like it".

On the one hand, this statement can be interpreted as positive motivation - the player wanted to develop, but on the other hand it may include an element of negative motivation, because the athlete had no more opportunities to develop in his own country, winning with everyone another season in a row. The other player in the case of which it may problematic to clearly define the type of motivation is the female respondent from interview 21 (Ukraine). The player was a member of the national team, on a daily basis she trained at a club back at home, while she indicated the following as the main reason for playing in the Polish league: "Possibility to develop as a player. I wouldn't have such an opportunity in Ukraine, in the local league". This is what she said about playing in the Polish league:

"Clubs in Lithuania and the Czech Republic had financial problems, so activists decided to start working with juniors, which was cheaper. So I decided to find a different club, I was looking for it in different countries, e.g. in France, Germany, but in all these places they wanted me to move and live there. It was only in Poland that they agreed for me to stay in Ukraine and travel to Poland for matches".

When interpreting this statement, it is easy to see elements of negative motivation, as the athlete said that she did not have the possibility of professional development in her own country. On the other hand, you can find elements of positive motivation in her statements as well, because she trained at home, she was in the national team, so she had conditions for training, but she wanted to play in the league to develop her sport skills. In addition, we found a financial component in the player's statement, as she added as a reason: "It was also money, the conditions I have here" (interview 21). It can therefore be concluded that her motivation also included this aspect. We classified the players from the Czech Republic and Ukraine described above in the group of mixed motivation, that is the one that included the elements of both positive and negative motivation ${ }^{8}$.

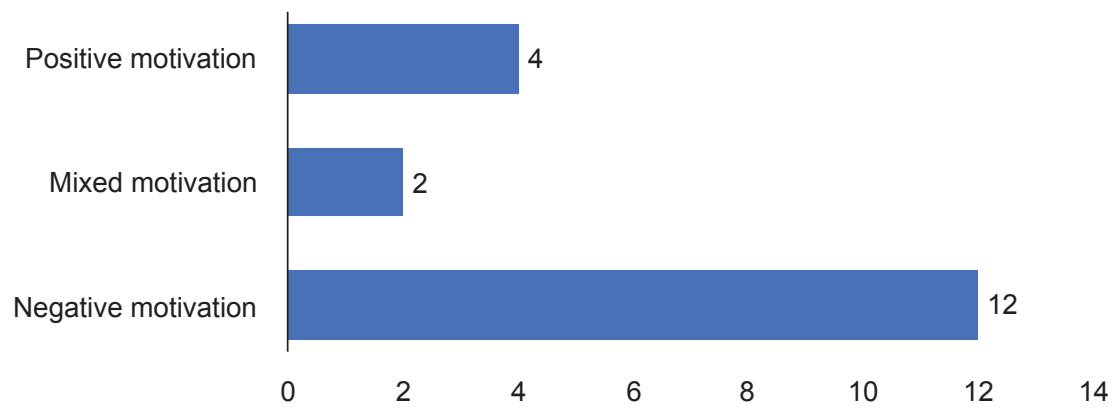

Figure 2. Declared motives for the arrival of the surveyed table tennis players to Poland from abroad (own research; absolute values with $\mathrm{n}=27$ )

The described players (both from China as well as India and Belarus), who wish to continue their tennis careers, match the category of ambitionists according to the typology by Maguire $(1999,2004)$ and Magee and Sugden (2002). The motivation of the surveyed players, either positive or negative, was connected with the plan to develop their professional careers.

\footnotetext{
${ }^{8}$ Interview 15 (Czech Republic, male), interview 21 (Ukraine, female).
} 
The respondents' motives related to their search for opportunities for further development were also related to the assessment of the sporting level of the Polish table tennis league compared to various countries and leagues, which preceded their decision to come to Poland. Among the statements of the majority of respondents (21 interviewees with $n=27$ ) there appeared a statement that the level of the Polish league is, in their opinion, very high. In interview 3, a respondent from England, who has won three national championships in singles and doubles, participated in the Olympic Games and won six medals in the Commonwealth Games, very important for the AngloSaxon world, said:

"Poland has one of the strongest leagues in Europe. Each team has at least two good players, there are strong players from China, Korea, a few strong Europeans. Overall, they represent a very high level of playing; I had a few options but I wanted to play in Eastern Europe. I chose to play here because it is a challenge for me that I wanted to take up. I want to meet different players and they have very strong players here, and it's a new challenge".

When asked about the level of the Polish league, a respondent from the Czech Republic (interview 15) said: "The Polish league is strong, offers good money, good proportions, so I tried here and I like it". The statement of a Czech female player - a seven-time champion in her own country, the European champion in mixed doubles, who has played in the Czech league and for a long time in the German league (interview 10) - seems to be particularly interesting:

"After a phone call from Poland, I readily agreed to play in Poland and after five years of playing here I have to say that I regret that this coach did not call me earlier, because I'm a much better player now, the system is better, everything is professionally done, even preparations for a poor game look like for the champions league. And there is a very good team here, so the motivation is high. I think that if I had played here earlier, I would be a much better player on an international scale. But it wasn't up to me".

Some of the respondents emphasised the importance of positive relations in the new club and the overall positive image of the country as motives to come and sometimes stay in a given country. We are talking primarily about two players of Asian origin (interview 2, Korea, male and interview 9, born in China, German citizenship, female) - they pointed to the friendly atmosphere in the club and good contact with the coach and club colleagues. When asked about the reason for playing in the league, a South Korean respondent who previously played in the German and Chinese leagues, replied:

"I didn't start playing here for money - money is better in Germany or France, but it's good here, the atmosphere is nice, everyone is nice, I don't want to play in another club" (interview 2).

In turn, the female player from interview 9 replied:

"For me, it doesn't matter where I play, it's important to have a good team, what matters is the atmosphere and the fact that I always feel good here".

As you can see, a positive atmosphere in the club can play an important role in choosing a given team, although in our research we also had examples of players who were not satisfied with the atmosphere and the way they were treated at the club during a certain period of work, and yet they stayed in the chosen clubs. Among others, this was the case for one player from China, living in Poland during the research period for already 14 years, who noted being treated as an object by the club (Some were saying "What do we need this Chinese guy for? When one Chinese comes, one has to go". And it wasn't nice") and a female player from Belarus, who did not feel accepted by her teammates:

"They are so unfriendly, when I win, they may not be on speaking terms with me for as long as two months. Last season, when I won, they didn't say a word to me for the whole year. (pause) It was hard for me and I was seeing a doctor at that time... . I don't talk to anyone, because when I try to say something, they look down on me. Take it or leave it. "(...) I didn't know anyone, and if Poles don't know someone they are not interested in getting to know them, they want to avoid them and at the beginning the girls would stick together, and I didn't know what to do by myself, I didn't know the language" (interview 1).

What seems interesting is that these players stayed with the club. This may indicate their very high motivation to play in this league in spite of all.

Most of the surveyed players treated playing in the Polish league as a certain stage in their career. However, there was one female respondent who started playing in the Polish league with the idea of changing her country of 
residence. The player had a difficult financial situation at home, and she described her country as follows: "There is chaos there; here it's civilised, and there like in the rural areas" (interview 20, Belarus, female). As she said earlier, her team mates did not treat her well, and in addition she was offered unfavourable financial conditions in comparison to other athletes. When asked if she would like to live in Poland, the player replied: "Yes, I would like to play here for some time and then start my own business.... In Poland, if I work I can live a normal life".

The respondents also mentioned being encouraged by their trainer and other players as the motive for their coming. This was the case for six athletes. Four of them were from China, one from South Korea and one from England. It was not their main motive, it usually appeared as an additional factor. In three cases, Chinese coaches had friends among Polish coaches and relying on this they offered their players to play in Poland. A Polish coach offered the player from Korea to play at the open Polish championship tournament:

"I played in the Polish Open a long time ago, and I met Tomasz who asked if I wanted to play in the Polish league. I was thinking a lot about it, asked if I could play here and in Korea at the same time. They agreed and I started playing here".

In two cases, the players were encouraged to play in the Polish league by their friends - the athlete from England was persuaded by his colleague from Poland, whom he knew well: "It was because of my team mate, he brought me here, we've known each other for over six years" (interview 3). In turn, the female player from China from interview 17 was persuaded by her Chinese colleague, who was playing in the Polish league at that time.

As we mentioned earlier, the respondents usually gave several reasons for playing in the Polish table tennis league. The female player from interview 1 decided to play in Poland mainly due to the lack of opportunities for further development in China, but on the other hand, she talked about the fear of going and playing in another country without a good command of the local language or English:

"I was a bit terrified, not that I was scared, I was so curious that I was anxious, you know when you get on a plane for the first time and you don't know the foreign language.... And I've also lost my luggage at the airport... ".

She also wanted to get to know Poland. At the beginning, the athlete hoped for a definite improvement of her life: "I imagined that Poland was clean, the people were rich, and everyone lived in single-family houses" (interview 1). In the case of this player, the stereotypical image of European countries as countries of prosperity and luxury came to the fore, without noticing the internal differentiation of Europe. However, when after coming to Poland, she learned that the country was not as rich as she anticipated. Yet, she was curious about new culture and people, started to learn Polish and attending a Polish high school. When asked if she spends more time with the Chinese or Poles, she replied: "I have little contact with the Chinese now... . I prefer the Poles" (interview 1). Another female player from China, although pointed to the desire to continue her career as the main reason of international migration, said also: "I had never left China before, and I was curious about what it was like abroad" (interview 8). The described curiosity of another country, the curiosity of Europe, is a motive that might classify her also to the group of the so-called nomadic cosmopolitan (Maguire 1999, p. 105; Magee and Sugden 2002, p. 432, Maguire et al. 2002, p. 33).

The results of our research indicate the changeability over time of the motives to play in foreign leagues and to continue working abroad, which is related to the length of a given player's sports career. The female player from interview 1 described above initially left her country as an ambitious migrant, she wanted to continue her career partly as a nomadic cosmopolitan, and over time she became a settler interested in the culture, language and willing to assimilate with Poles. Some respondents, especially those with longer training experience, admitted that when they were starting their careers in foreign leagues, the most important for them was development of their sports skills and the opportunity to play with better players. Only now, when they felt they were closer to the end of their sport careers, money began to matter more. A Chinese player with Slovak citizenship, who started his adventure with a foreign league at the age of 16, and before coming to Poland played in Germany, Russia and, briefly, in Slovakia, said during the interview (he was 20 at the time of the research):

"Now I play for money, but at the beginning what mattered was experience and continued playing. I tried everything to make my dreams come true, now I am thinking about the future, I want to get married, so I need money.... And would you like to play in a league in some other country? Yes, maybe they pay more elsewhere, and I would definitely go there" (interview 12).

The female respondent from the Czech Republic recalled the time when she was starting in the German league: 
"It was the best league, it was great for me. Then I would even play for free, because it was a great opportunity for me”.

At the age of 28 she returned to the Czech Republic and played in the league there. When she thought it was the end of her sporting career, a Polish coach called her. This is how she recalls it:

"A coach from Poland, a table tennis fanatic, who knows all the players, me included, because I'm already an old player and I often play at various competitions, contacted me. It was a cool thing for me. I was in my 30's at that time (this is my fifth season here) and I thought it was the final whistle for me to play elsewhere. (...) Now it's simply about money and continued career".

The more autotelic motivation of respondents related to the search for opportunities for further development and gaining new experiences gave way to a more pragmatic approach to life, which is financial motivation. As can be seen from the statements of the players in interviews 10 and 12, this change is also connected with gradual approaching to the final stage of a sports career, which is shorter than other professional careers, and the need to financially secure oneself for the next stages of life, which is related to starting a family and taking on new social roles.

Another example of a player who was rather at the end of her sports career is a 23-year-old tennis player from China (interview 18). She used to play in leagues in Sweden and Denmark, and came to Poland for financial reasons. When asked about the most important reason for playing in the Polish league, she replied: "Money .... And apart from that, I wanted to play in some other country, in Europe". When asked if she would like to play in some other league, she replied: "If they offer good money, I can think about it". The player emphasised that in the future she wants to have a job in China and dreams of becoming a journalist. According to her statements, she did not associate her future with table tennis. The players described above represent a group of economic migrants, but as mentioned before, their motives to play in the league have changed over time. There is also a group of players who decided to come to Poland attracted by the prospects of earning better money and did not mention that they had other reasons to play when they played in other leagues before. It is possible, however, that they also did not play for money initially, however they did not say anything about it (Agergaard 2008, p. 7; Maguire et al. 2002, p. 33).

It was also interesting to analyse what, according to the surveyed coaches, motivates foreign players to play in the Polish league and what are the reasons for hiring foreign players by Polish clubs. Two main reasons appeared in the trainers' statements - financial one (four respondents) and career development (two respondents). Two coaches came to the conclusion that players are motivated by mixed reasons - mostly financial and related to career development. The coach from interview 4 said that the Chinese coming to play in the league are looking for contacts to do business with China, "and when looking for contacts, they are looking for opportunities to earn money". The coach gave an example of a player who,

\footnotetext{
"When he arrived [to Poland], he immediately started thinking in terms of how many containers and what would be needed. And apart from using tennis in a sporting sense, as an opportunity to fulfil your ambitions in this respect, to show yourself in China after coming back, from the beginning it was the desire to combine these sport goals with doing business. This player has been importing containers with equipment for years, because selling it here is profitable for him".
}

When asked about the main reason why Chinese players come to play in Polish leagues, he replied:

"We may wonder. As far as I can say based on my contacts with them, there is no one reason, but rather a mixture of reasons. It is not just one”.

The coach from interview 5:

"What do you think, why do foreign players want to play in the Polish league, what are the main reasons for this? At some level, everyone wants to have a way to make a living. Year by year, the status of the clubs in Poland is increasing. We can talk about contracting foreign players. And there are some clubs that can talk about contracting top, best players, but let's not exaggerate, economic factors matter here. For example, Bundesliga, French league - the leagues are much richer there. So good players go mainly there. On the other hand, 2-3 men's clubs in Poland are organisationally very efficient".

The coach from interview 8: 
"In China, some of the players outside of the central training, who were not admitted to the national team, had a choice - either to go abroad or work in their country; many good players often decided to go abroad and found themselves in Poland - this is how the first Chinese player came to Poland. This is the way for them to continue playing tennis and develop".

The coach from interview 2 when asked: What do you think are the reasons for foreign players to play in Poland?" replied:

"They themselves also care about playing with the good players, because our league is really very strong. They also develop, so the club benefits from it and so do they. It's a win-win situation".

In turn, the coach from interview 1 answered the same question in the following way:

"The reasons are purely financial. They get a financial offer from a club that is interesting to them, and that's why they choose our clubs and our league, not clubs of other countries".

The surveyed coaches were also asked about the reasons for hiring foreign players by Polish clubs. The coach from interview 7 replied:

"In the past, foreign players were certainly better and cheaper than Poles, and now they are better, but certainly not cheaper".

In turn, the coach from interview 4, when asked about the reasons for hiring foreign players in Polish leagues, replied:

"Mainly, because there is a deficit of Polish players. In order to compete at the top league level, we need good players. There are very few such good Poles, so you have to bring players from other countries, it turned out that despite the higher sports level foreign players (Belarus, Ukraine, Russia) had lower or the same financial requirements and represented a higher level - they played better for lower or the same money. When these opportunities were over, the clubs reached to Asia".

\section{Conclusions and discussion}

The reasons why the surveyed players decided to come to Poland were varied and included both pull factors mentioned by Elliott (2012) and factors pushing the players away from their European and Asian home countries. Among the motives mentioned by the respondents, the major ones - with the exception of Chinese players - seem to be the aspiration to continue their professional career and to develop as players. Similar results were obtained by Botelho and Agergaard (2011). In their research on female footballers from North America and Africa, they asked, among others, about the motives of the departure and playing in Scandinavian countries. The results of their research indicated that the main reason for the migration process of footballers was the desire to develop sports careers and gain experience in football, which was justified by migration "for the love of the game" (2011, p. 817).

The majority of the surveyed table tennis players did not indicate one main factor decisive for their playing for a foreign club, but usually mentioned several similarly important motives. For some of them, the decisive criterion was the perceived high level of the Polish table tennis league, which in their opinion was only slightly lower compared to the best leagues in Europe, that is French and German, offering very good employment conditions for athletes. For other respondents, good financial conditions offered by Polish clubs were of key importance. Numerous players stressed that the decision to come to Poland was also about improving their quality of life. Some also emphasised that Polish clubs give greater freedom as to the player's place of residence and do not require permanent residence in Poland, thanks to which players can develop their skills in a demanding league without the need to leave their homes (the case of a player from Ukraine, interview 21). With regard to factors pushing the players out of the sports market in their country of origin, these were particularly important in the case of Chinese players representing a very high level of sport skills, however slightly lower than the level required for the Chinese national team. For these players, there were no prospects of further sports development in the country of origin. In China, we can observe a phenomenon of "overproduction" of well-qualified table tennis players, which means that a significant number of good players cannot find employment in clubs in their country of origin. The phenomenon of "overproduction" of players in emission countries was also described by Elliott (2012), who gave the examples of 
basketball players and hockey players from the USA. In our research, it was visible among table tennis players from China. Athletes, wanting to continue playing table tennis and be able to earn money on it, were forced to look for a place in foreign leagues, e.g. in Poland or other well-off European countries. We might include them in the exile and mercenary type of sport migrants. Sport opened many Chinese athletes a way out from Chinese communist country and for many athletes who could experience liberal societies of the West it was a one way trip, ending with permanent settlement and sometimes other country citizenship. Interestingly, Kardaszewicz (2019, p. 354) depicting changes in Chinese migration to Poland, notices that present day immigrants from China (in contrary to labour migrants from Ukraine) are not driven by economy, but mainly looking for better quality of life, good and affordable education for their children" and because of "a struggle against a state-sponsored model of achievement, which reflects both resistance and compliance to established educational norms and values" Kardaszewicz (2019, p. 355). Elements of this way of thinking we could observe in case of interviewed Chinese athletes from interview 1 and 8.

It is worth stressing that most of the respondents declared combination of reasons for coming to Poland and playing in the Polish table tennis league. They included both the desire to play in a league with the highest possible sporting level (the ambitionist type dominating among our European respondents and not concerning Asian respondents), obtaining satisfactory remuneration for the work performed (the mercenary type), possibility of living in a country with a higher economic level and better life quality, but also interest in a new country, working in a good atmosphere. The latter would be probably the motives of the nomadic athlete-migrant type. The results of our research confirm Maguire's (2004, p. 480), comments that the categories of migration typology are not rigidly established, and their various aspects overlap and blur, creating various combinations (Maguire 1999, p. 105). Especially interesting combination concerned our Chinese respondents who on the one hand were mercenaries, but on the other were semi-voluntary exiles pushed from the Chinese sport system seeking better life quality in Europe.

\section{Ethics approval and informed consent}

Research study was carried out upon the prior consent of the athlete and coach respondents and the Józef Pilsudski University of Physical Education in Warsaw research department.

\section{Competing interests}

There are no conflicts of interest associated with this manuscript, financial or otherwise.

\section{Funding}

This scientific research was supported by the Polish Ministry of Science and Higher Education under grant 'Sport migrants in Polish table tennis leagues', as part of the Science School no. 2 ('The socio-humanistic school of physical culture research') of the Józef Pilsudski University of Physical Education in Warsaw, Poland.

\section{References}

Agergaard, S. (2008). Elite athletes as migrants in Danish women's handball, International Review for the Sociology of Sport, 43(1), 5-18. https://doi.org/10.1177/1012690208093471

Botelho, V. L., Agergaard, S. (2011). Moving for the love of the game? International migration of female footballers into Scandinavian countries. Soccer \& Society, 12(6), 806-819. https://doi.org/10.1080/14660970.2011.609681

Elliott, R. (2012). New Europe, new chances? The migration of professional footballers to Poland's Ekstraklasa, International Review for the Sociology of Sport, 48(6), 736-750. https://doi.org/10.1177/1012690212446472

Kardaszewicz, K. (2019). New rules of the game? Education and governmentality in Chinese migration to Poland, Asian and Pacific Migration Journal, 28(3), 353-376. https://doi.org/10.1177/0117196819877004

Lenartowicz, M. (2016). „Dziś będę Polakiem”. Migracje sportowe i zmiany obywatelstwa przez wyczynowych sportowców [„,Today I'm going to be Polish. Sport migrations and citizenship changes among professional athletes]. In J. Kosiewicz, E. Małolepszy \& T. Drozdek-Małolepsza (Eds.), Filozoficzne i społeczne aspekty sportu $i$ turystyki [Philosophical and social aspects of sport and tourism] (pp. 117-126). Wyd. Akademii im. Jana Długosza w Częstochowie.

Lenartowicz, M. \& Jankowski, K. W. (2014). Reconstructing class sport practices in Poland, Physical Culture and Sport. Studies and Research, 63(1), 12-19. https://doi.org/10.2478/pcssr-2014-0018 
Lenartowicz, M. \& Ciok, A. (2020). Foreign players in top Polish table tennis leagues: sport cultures differences and perceived impact on Polish table tennis, Acta Universitatis Lodziensis. Folia Sociologica, 75, 15-32, https://doi. org/10.18778/0208-600X.75.02

Maguire, J., Bale, J. (1994). Sports Labour Migration in the Global Arena, In J. Bale, J. Maguire (Eds.), The Global Sports Arena. Athletic Talent Migration in an Interdependent World (pp. 1-24). Frank Cass Publishers.

Magee, J., Sugden, J. (2002). The world at their feet - professional football and international labor migration, Journal of Sport and Social Issues, 26(4), 421-437. https://doi.org/10.1177/0193732502238257

Maguire, J. (1999). Global sport: Identities, societies, civilizations, Cambridge, Polity.

Maguire, J. (2004). Sport labour migration revisited, Journal of Sport \& Social Issues, 28(4), 477-482. https://doi.or$\mathrm{g} / 10.1177 / 0193723504269914$

Maguire, J. A., Jarvie G., Bradley, J. \& Mansfield, L. (2002). Sport Worlds. A Sociological Perspective, Champaign, IL: Human Kinetics.

Pilarski, S. (2014). „Odmówił powrotu do kraju” - ucieczki piłkarzy z PRL na Zachód [Refused to come back - exiles of soccer players from communist Poland to the West]. Pamięć $i$ Sprawiedliwość, 13(20), 387-421.

Rider, T.C. (2013). Eastern Europe's Unwanted: Exiled Athletes and the Olympic Games, 1948-1964. Journal of Sport History, 40(3), 435-453. https://www.muse.jhu.edu/article/537278

Rojo, J. R., Njororai Simiyu, W. W. \& Starepravo, F. A. (2020). Research on sports migration: an analysis of methodological procedures. Journal of Physical Education \& Sport, 20(2), 546-553. https://doi.org/10.7752/jpes.2020.02081

This is Open Access article distributed under the terms of CC-BY-NC-ND 4.0 International License. 